Ulrich von Wilamowitz-Moellendorff

Geschichte der Philologie 
Ulrich von Wilamowitz-Moellendorff

\section{Geschichte der Philologie}

Mit einem Nachwort und Register von Albert Henrichs

3. Auflage

Neudruck der Erstauflage von 1921

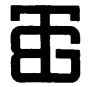

Springer Fachmedien Wiesbaden GmbH 1998 
Die deutsche Bibliothek - CIP-Einheitsaufnahme

Wilamowitz-Moellendorff, Ulrich von:

Geschichte der Philologie / Ulrich von Wilamowitz-Moellendorff. -

Neudr. der Erstaufl. von 1921,3. Aufl. /

mit einem Nachw. und Reg. von Albert Henrichs.

ISBN 978-3-663-12140-4 ISBN 978-3-663-12139-8 (eBook)

DOI 10.1007/978-3-663-12139-8

Das Werk einschließlich aller seiner Teile ist urheberrechtlich geschützt. Jede Verwertung außerhalb der engen Grenzen des Urheberrechtsgesetzes ist ohne Zustimmung des Verlages unzulässig und strafbar. Das gilt besonders für Vervielfältigungen, Übersetzungen, Mikroverfilmungen und die Einspeicherung und Verarbeitung in elektronischen Systemen.

(C) Springer Fachmedien Wiesbaden 1998

Originally published by B. G. Teubner Stuttgart und Leipzig in 1998

Softcover reprint of the hardcover 3rd edition 1998

Gesamtherstellung: Druckerei zu Altenburg GmbH 